\title{
Analysis of Low Amylose and Processability Fractured Endosperms Derived from Somatic Variation
}

\author{
Gihwan $\mathrm{Yi}^{1}$, Kyung Min Kim ${ }^{2 *}$ \\ ${ }^{1}$ Department of Farm Management, College of Agriculture \& Life Science, Kyungpook National University, Gunwi-gun, South Ko- \\ rea; ${ }^{2}$ Division of Plant Biosciences, School of Applied Biosciences, College of Agriculture and Life Science, Kyungpook National \\ University, Daegu, South Korea. \\ Email: ${ }^{*} k \mathrm{~km} @$ knu.ac.kr
}

Received February $21^{\text {st }}, 2013$; revised March $27^{\text {th }}, 2013$; accepted April $9^{\text {th }}, 2013$

Copyright (C) 2013 Gihwan Yi, Kyung Min Kim. This is an open access article distributed under the Creative Commons Attribution License, which permits unrestricted use, distribution, and reproduction in any medium, provided the original work is properly cited.

\begin{abstract}
Recently, improving eating quality and processing properties has become one of the most important objectives in japonica rice breeding programs in Korea. This study was carried out to determine the agronomy and physicochemical characteristics of the opaque endosperm rice "S-21-3-8" regenerated from seed-derived callus culture of a rice cultivar, "Ilpum". $S_{3}$ generation of opaque endosperm mutants selected from pedigree breeding was used for analysis of agronomic and physicochemical traits. Genetic segregation was observed at the highest frequency among opaque endosperm mutants, being present in $85.7 \%$ (12/14 lines) of the entire opaque lines. However, the major agricultural characteristics and grain traits of "S-21-3-8" were similar to those of a donor cultivar, "Ilpum". "S-21-3-8" showed significantly lower $(10.6 \%)$ amylose than those (17.7\%) of "Ilpum" in brown rice, while the protein levels were similar to those of the donor plant. The grain hardness of "S-21-3-8" $\left(1.67 \mathrm{kgf} / \mathrm{mm}^{2}\right)$ was lower than that of "Ilpum" $\left(1.97 \mathrm{kgf} / \mathrm{mm}^{2}\right)$, resulting in a high flour-milling percentage. The loosely packed starch granules of "S-21-3-8" in the opaque endosperm were demonstrated by SEM analysis of cross-sectioned rice grains. The opaque endosperm mutants that were of somaclonal variations in the tissue culture will lead to improved eating quality and processing properties of rice.
\end{abstract}

Keywords: Rice; Opaque; Endosperm; Flour-Milling; Starch Granules

\section{Introduction}

$45 \%$ of the world's population, especially in Asia, more than $90 \%$ of the rice, and there has recently been increasing demand for high quality rice in the international market [1]. Korea was since the 1990s by an increasing preference for eating quality than Tongil type varieties not grown longer the middle of 1970s [2]. The traits of rice grain quality include milling quality, appearance quality, cooking and eating quality, and nutritional quality, of which cooking and eating quality is the most important component for the Asian customers who mainly consume rice [3]. Plant tissue culture as a means of developing new quality crops has been extensively used for many species. Cytologic and genetic models of plants without chemical mutagen components of the medium during the differentiation through tissue have revealed phenotypic variants among somaclonal plants regenerated from almost all plant calluses [4,5]. There was wide variation in seed fertility, culm length and heading date

${ }^{*}$ Corresponding author. in tissue culture. The variations that occur in the future generations of rice tissue culture include the major agronomic characteristics [5-10], such as panicles, frequency of fertile tillers per plant, plant types and flag leaf length [11], as well as protein or lysine physicochemical composition $[12,13]$, physiological damage and salt tolerance $[6,14]$. Throughout plant regeneration occurs being known as rice [15] like that well blast resistance [7], bacterial leaf blight [16], sheath blight [7,16,17], blight resistance, and agronomic traits [18]. Somaclonal variations can be introduced with relatively high incidence, but wide variations in seed culture, suggesting that the new variations are less strong than formerly assumed. The attention of breeders to improved varieties of crops due to the advantage that occurs one or two ratios only object visible and homozygous mutants on high frequency of somatic mutations has been the subject of somaclonal variation. Organ specificity and variation among somaclones has been observed for a wide array of characteristics. Studies of the homozygous variants of the genetic mechanisms 
that give rise to such variation will prove a productive field of investigation. Somaclonal variants are already leading to improvements of sugar cane and potato cultivars, and the breeding of new floricultural varieties. We shall also argue that somaclonal variants can provide a valuable adjunct to plant improvement $[19,20]$. During seed culture, many variants have been recognized based on agricultural traits, grain appearance, chemical components, physicochemical elements and starch structure, all of which are considered to be regulated and integrated. The phenotypes of opaque endosperm mutants in grain variants include floury, glutinous, shrunken, dull, white belly, and white-core endosperms [21]. Opaque seed maturity or metabolic processes are associated with the storage of nutrients or interpretation of the material, genetic apparatus, and identification of the gene that encodes the enzyme of starch biosynthesis has characteristics [21,22]. It is reported that white core in rice grain facilitate brewing process of wine [23]. The value of some of the opaque rice for food evaluated. The objective of this study was to identify the eating quality traits of opaque endosperms of somaclonal variants grown in tissue culture to enable effective approaches to improvement of eating quality of japonica rice in South Korea.

\section{Experimental Part}

\subsection{Experimental Environments and Cultural Management}

Fourteen lines of opaque variants in endosperm mutation were planted using the $S_{3}$ seeds of regenerated plants of somatic mutations derived from "Ilpum" and "Baekjinju" as a control. Fourteen lines of opaque variants were sown in the Gunwi experimental field of Kyungpook National University in the 2012 growing season. The opaque endosperm lines were sown in on plastic tunnel-seed beds on 30th April and then 32-day-old seedlings were transplanted in one row using a distance of $15 \mathrm{~cm}$ between plants and a row space of $30 \mathrm{~cm}$. The field was managed under standard practices with an application of fertilizer at the rate of $110 \mathrm{~kg} \mathrm{~N} / \mathrm{ha}, 45 \mathrm{~kg} \mathrm{P}_{2} \mathrm{O}_{5} / \mathrm{ha}$, and $57 \mathrm{~kg}$ $\mathrm{K}_{2} \mathrm{O} /$ ha, which was recommended by the rural development administration (RDA) of Korea. After harvest, the fourteen lines of opaque variants, the donor plant, "Ilpum" and "baekjinju" were naturally dried and stored at room temperature for three months and hulled to produce brown rice before being evaluated for their opaque characteristics.

\subsection{Physicochemical Analysis of Opaque Endosperms}

The agronomic traits including heading date, culm length, panicle length and the number of panicles per hill were investigated for $\mathrm{S}_{3}$ opaque endosperm plants, after fifty days heading dates. In order to investigate the characteristics of grains, length, the width, the thickness of brown rice to fifty grains three replications by Vernier Caliper (MITUTOYO, CD-15CP) were measured, respectively. Grain length/width ratio was calculated by the product of length/width ratio. In addition, thousand grains of weight using electronic scales (ARD 120) investigated hundred grains three replications and were calculated to describe relative dimension of grain. Mean values, standard deviations were calculated by means of Microsoft Excel. Opaque grains of chemical composition to investigate, the amylose characteristics of brown rice of three replications for each line was determined Infrared Reflectance spectroscopic analysis ((T80 + UV/VIS Spectrometer), the protein content of brown rice of three replications for each line was determined by (IRS, Kjelter TM 8400 Analyzer Unit). In order to investigate the physical characteristics, the degree of hardness of opaque lines survey using a steel ball indenter indentation marks made on the initiative of the specimen, when Value divided by the surface area calculated from the diameter of the indentation marks load of indentation marks $\left(\mathrm{mm}^{2}\right)$, Brinell hardness tester hardness grains (KHT-40 N, Japan) is a 10 grains repeated three replications in the survey are presented. Chromaticity of each sample using a colorimeter (color techno system JS555), L (lightness), $\pm \mathrm{a}$ (red/green), $\pm \mathrm{b}$ (yellow/blue) values were measured. Two dried seed samples representing each sample were selected randomly for examination. Samples for the scanning electron microscope (SEM, Scanning Electron Microscope, Hitachi S-3000 N) were pre-fixed, dried to a critical point, and coated with gold. The samples were observed at an accelerating voltage of $15 \mathrm{kV}$.

\section{Results and Discussion}

\subsection{Major Agricultural Characteristics of the Opaque Endosperm}

The traits of opaque endosperm mutants derived from progenies of somatic mutants were analyzed. The means and standard deviations of fourteen opaque mutants were evaluated for grain opaque characteristics. The major agricultural characteristics of somatic mutants derived from tissue culture were as follows (Table 1). Those with a heading date of $1-2$ days difference from the donor plant, "Ilpum" were similar. In addition, the culm length of plant phenotypes "W-1002-5" and "S-21-3-6" were similar to the donor plant, while those of "S-21-3-3" and "W-1002-2" were longer. Most of the opaque endosperm lines had shorter culm lengths. Comparison of the panicle length and panicles per plant indicated that most opaque endosperms were similar to the donor plant, except for "S-19-2-5". Ripened grain (\%) related to yield per plant 
Table 1. Agricultural characteristics of opaque endosperm mutants derived from brown rice.

\begin{tabular}{|c|c|c|c|c|c|c|c|}
\hline Pedigree & $\begin{array}{l}\text { Heading date } \\
\text { (day/month) }\end{array}$ & $\begin{array}{l}\text { Culm length } \\
\text { (cm) }\end{array}$ & $\begin{array}{l}\text { Panicle length } \\
\text { (cm) }\end{array}$ & $\begin{array}{c}\text { No. of } \\
\text { Panicles }\end{array}$ & $\begin{array}{c}\text { Ripened ratio } \\
(\%)\end{array}$ & $\begin{array}{c}\text { Yield } \\
(\mathrm{kg} / 10 \mathrm{a})\end{array}$ & Index $(\%)$ \\
\hline W-1001-2 & 3rd of Aug. & $44 \pm 3.1^{1)}$ & $20 \pm 0.8$ & $8 \pm 4.3$ & 53.8 & 428 & 72 \\
\hline W-1001-4 & 3rd of Aug. & $42 \pm 3.8$ & $20 \pm 0.9$ & $13 \pm 6.1$ & 12.7 & 184 & 31 \\
\hline W-1001-8 & 3rd of Aug. & $43 \pm 2.4$ & $20 \pm 0.8$ & $15 \pm 1.9$ & 6.5 & 148 & 25 \\
\hline W-1002-5 & 4th of Aug. & $41 \pm 1.8$ & $21 \pm 1.6$ & $15 \pm 2.7$ & 14.5 & 195 & 33 \\
\hline S-19-2-2 & 3rd of Aug. & $43 \pm 4.3$ & $20 \pm 0.8$ & $16 \pm 2.4$ & 30.2 & 288 & 49 \\
\hline S-19-2-3 & 3rd of Aug. & $41 \pm 4.0$ & $18 \pm 2.3$ & $16 \pm 4.6$ & 12.6 & 184 & 31 \\
\hline S-19-2-4 & 3rd of Aug. & $43 \pm 2.6$ & $19 \pm 1.3$ & $15 \pm 2.9$ & 25.4 & 260 & 44 \\
\hline W-1004-3 & 3rd of Aug. & $41 \pm 4.2$ & $20 \pm 0.8$ & $11 \pm 2.8$ & 5.1 & 139 & 24 \\
\hline W-1004-12 & 3rd of Aug. & $42 \pm 1.6$ & $19 \pm 1.6$ & $9 \pm 2.0$ & 6.7 & 149 & 25 \\
\hline S-21-3-8 & 3rd of Aug. & $71 \pm 5.1$ & $20 \pm 5.2$ & $13 \pm 1.8$ & 78.1 & 572 & 97 \\
\hline S-19-2--5 & 3rd of Aug. & $44 \pm 2.8$ & $21 \pm 0.9$ & $11 \pm 3.0$ & 40.6 & 350 & 59 \\
\hline W-1002-2 & 3rd of Aug. & $67 \pm 5.1$ & $22 \pm 1.8$ & $14 \pm 4.9$ & 57.9 & 452 & 76 \\
\hline W-1002-5 & 3rd of Aug. & $64 \pm 4.0$ & $22 \pm 1.5$ & $13 \pm 3.4$ & 70.5 & 527 & 89 \\
\hline S-21-3--6 & 3rd of Aug. & $65 \pm 1.6$ & $23 \pm 1.5$ & $14 \pm 2.2$ & 41.8 & 357 & 60 \\
\hline Ilpum & 2nd of Aug. & $65 \pm 1.7$ & $20 \pm 0.5$ & $12 \pm 2.0$ & 81.6 & 593 & 100 \\
\hline Baekjinju & 17th of Aug. & $64 \pm 2.3$ & $21 \pm 0.3$ & $11 \pm 1.7$ & 71.4 & 533 & 90 \\
\hline
\end{tabular}

${ }^{1)}$ The data are presented as the Mean \pm SD.

was $81.6 \%$ for the donor plant, while that between most of the opaque endosperm lines and each plant was relatively different with ripened grain. When compared to the opaque endosperm lines, "S-21-3-8" and "W-1002-5" had much higher percentages of ripened grains of $(78.1 \%$ and $70.5 \%$, respectively). The yield of "S-21-3-8" and "W-1002-5" was 3\% lower than the donor plant. All of these changes showed a functional nature of rice, such that "Baekjinju" derived from "Ilpum" mutant showed $10 \%$ decrease in generally to typical example.

\subsection{Grain Characteristics of Opaque Endosperm Mutants in Brown Rice}

The grain length/width ratio was not significantly different between opaque endosperm mutants and the donor plant (Table 2, Figure 1). The heterozygous and homozygous segregation of opaque endosperm grains was relatively higher than those of the donor plant, but this difference was not significant. All homozygous plants ("S-21-3-8", "S-21-3-6") produced opaque seeds, whereas the heterozygous plants segregated a white-core, whitebelly to opaque endosperm mutants. When opaque endosperms were separated from the donor plant, we found that the weight of 1000 opaque endosperms was

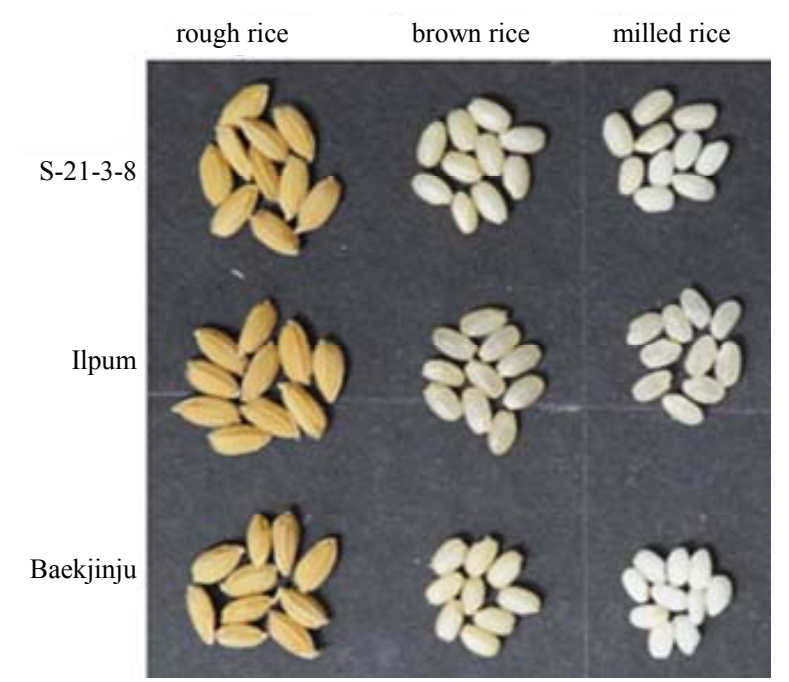

Figure 1. Comparison of grain appearance of "S-21-3-8" mutants of brown rice.

just $71 \%-103.5 \%$ of that of 1000 normal seeds. Most of the grain length/width of opaque endosperm mutants had elliptical grains (1.8 - 2.1), except for "S-21-3-8" (1.8) and "Baekjinju" (1.6), as well as a favorable appearance quality for Korea. 
Table 2. Mean value for grain appearance of opaque endosperm mutants.

\begin{tabular}{|c|c|c|c|c|c|c|}
\hline \multirow{2}{*}{ Pedigree } & \multicolumn{3}{|c|}{ Brown rice } & \multirow{2}{*}{ Length/Width } & \multirow{2}{*}{1000 grain $(\mathrm{g})$} & \multirow{2}{*}{ Character } \\
\hline & Length (mm) & Width (mm) & Thickness (mm) & & & \\
\hline W-1001-2 & $5.3 \pm 0.14^{1)}$ & $2.6 \pm 0.15$ & $1.8 \pm 0.14$ & 2.0 & 19.8 & Opaque seg. \\
\hline W-1001-4 & $5.3 \pm 0.19$ & $2.6 \pm 0.19$ & $1.8 \pm 0.14$ & 2.0 & 19.3 & Opaque seg. \\
\hline W-1001-8 & $5.3 \pm 0.21$ & $2.7 \pm 0.19$ & $1.6 \pm 0.16$ & 2.0 & 18.2 & Opaque seg. \\
\hline W-1002-5 & $5.3 \pm 0.20$ & $2.5 \pm 0.21$ & $1.8 \pm 0.07$ & 2.1 & 18.8 & Opaque seg. \\
\hline S-19-2-2 & $5.2 \pm 0.34$ & $2.4 \pm 0.18$ & $1.8 \pm 0.22$ & 2.2 & 19.3 & Opaque seg. \\
\hline S-19-2-3 & $5.2 \pm 0.17$ & $2.5 \pm 0.21$ & $1.7 \pm 0.17$ & 2.1 & 18.6 & Opaque seg. \\
\hline S-19-2-4 & $5.1 \pm 0.33$ & $2.5 \pm 0.27$ & $1.8 \pm 0.84$ & 2.0 & 18.5 & Opaque seg. \\
\hline W-1004-3 & $5.2 \pm 0.32$ & $2.6 \pm 0.19$ & $1.8 \pm 0.71$ & 2.0 & 18.2 & Opaque seg. \\
\hline W-1004-12 & $5.1 \pm 0.28$ & $2.6 \pm 0.32$ & $1.8 \pm 0.04$ & 2.0 & 19.1 & Opaque seg. \\
\hline S-21-3-8 & $5.1 \pm 0.21$ & $2.9 \pm 0.20$ & $1.8 \pm 0.23$ & 1.8 & 20.7 & Opaque \\
\hline S-19-2--5 & $5.1 \pm 0.28$ & $2.7 \pm 0.17$ & $1.8 \pm 0.16$ & 1.9 & 18.2 & Opaque seg. \\
\hline SW-1002-2 & $5.0 \pm 0.28$ & $2.6 \pm 0.17$ & $1.8 \pm 0.14$ & 1.9 & 18.0 & Opaque seg. \\
\hline W-1002-5 & $5.0 \pm 0.18$ & $2.7 \pm 0.18$ & $1.8 \pm 0.12$ & 1.9 & 18.7 & Opaque seg. \\
\hline S-21-3--6 & $4.9 \pm 0.26$ & $2.5 \pm 0.13$ & $1.6 \pm 0.10$ & 2.0 & 14.2 & Opaque \\
\hline Ilpum & $5.1 \pm 0.18$ & $2.7 \pm 0.18$ & $1.9 \pm 0.18$ & 1.9 & 20.0 & \\
\hline Baekjinju & $4.7 \pm 0.14$ & $2.9 \pm 0.25$ & $1.8 \pm 0.27$ & 1.6 & 18.3 & \\
\hline
\end{tabular}

${ }^{1)}$ The data are presented as the Mean \pm SD.

\subsection{Chemical Composition of Opaque Endosperm Mutants in Brown Rice}

Chemical properties of endosperms were compared between the opaque mutant and donor cultivar. There was no significant difference in proteins (Table 3). However, the amylose content of "S-21-3-8" was decreased (10.6\% $\pm 0.1 \%)$ when compared to that of that of "Ilpum" $(17.7 \%$ $\pm 0.08 \%)$, as was that of "S-21-3-6" (16.4\% $\pm 0.06 \%)$. In addition, the "S-21-3-8" amylose content was decreased by $0.8 \%$ relative to that of "Baekjinju" (11.4\%). Furthermore, the "S-21-3-6" amylose content was decreased by $1.3 \%$ relative to that of "Ilpum", while the protein content was slightly increased by $2.9 \%$ when compared to "Baekjinju". Protein of that next main ingredient in rice contains an average of 5\% to $8 \%$ in all samples. Palatability and protein content were negatively correlated. This is because a protein layer was formed around the starch granules, reducing the elasticity and viscosity of rice after cooking and directly affecting its gelatinization properties [24]. Genetic analysis revealed that opaque rice endosperms are closely related to low amylose content [25]. Opaque endosperms may be composed of the more highly branched starch granule amylopectin, which would account for its opaque nature and low amylase content [26]. The protein content of "S-21-3-8" was similar to that of the donor plant. Protein was primarily in the aleurone layer of the endosperm between the starch granules [24]. Generally higher protein content during cooking due to the excellent one color, absorbent degradation of starch gelatinization and swelling suppression nutrition in the evaluation of the palatability is obtained in low score [27].

\subsection{Physicochemical Analysis of Opaque Endosperm Mutants in Brown Rice}

To determine if the opaque endosperm system could be used to enforce integrity and workability, to the hardness and colorimetric value of "S-21-3-8" and "S-21-3-6" were measured (Table 4). The results revealed that the hardness of "S-21-3-8" $\left(1.67 \pm 0.25 \mathrm{kgf} / \mathrm{mm}^{2}\right)$ and "S-21-3-6" $\left(1.58 \pm 0.63 \mathrm{kgf} / \mathrm{mm}^{2}\right)$ was lower than that of the donor plant $\left(1.97 \mathrm{kgf} / \mathrm{mm}^{2}\right)$ as well as that of "Baekjinju" (2.97 $\pm 0.46 \mathrm{kgf} / \mathrm{mm}^{2}$ ), indicating that the hardness of these strains was too low to enable efficient use for rice flour. 
Table 3. Chemical composition of opaque endosperm mutants in brown rice.

\begin{tabular}{cccc}
\hline \multirow{2}{*}{ Pedigree } & \multicolumn{2}{c}{ Brown rice } & Moisture (\%) $^{*}$ \\
\cline { 2 - 4 } & Amylose (\%) & Protein (\%) & $12.3 \pm 0.1 \mathrm{a}$ \\
S-21-3-8 & $10.6 \pm 0.2 \mathrm{c}^{\mathbf{1}}$ & $7.2 \pm 0.1 \mathrm{~b}$ & $11.9 \pm 0.1 \mathrm{a}$ \\
S-21-3-6 & $16.4 \pm 0.1 \mathrm{a}$ & $9.2 \pm 0.3 \mathrm{a}$ & $12.1 \pm 0.3 \mathrm{a}$ \\
Ilpum & $17.7 \pm 0.1 \mathrm{a}$ & $7.6 \pm 0.4 \mathrm{~b}$ & $11.0 \pm 0.3 \mathrm{a}$ \\
\hline
\end{tabular}

"In a column, means followed by a common letter are not significantly different at the $1 \%$ level by DMRT, ${ }^{1)}$ The data are presented as the Mean \pm SD.

Table 4. Hardness and colorimetry of opaque endosperm mutants in brown rice.

\begin{tabular}{ccccc}
\hline \multirow{2}{*}{$\begin{array}{c}\text { Pedigree } \\
\text { and cultivar }\end{array}$} & Hardness $\left(\mathrm{kgf} / \mathrm{mm}^{2}\right)^{*}$ & \multicolumn{3}{c}{ Colorimetry } \\
\cline { 3 - 5 } & $1.67 \pm 0.25 \mathrm{~b}^{1)}$ & L (lightness) & $\pm \mathrm{a}$ (red/green) & $\pm \mathrm{b}$ (yellow/blue) \\
\hline S-21-3-8 & $1.58 \pm 0.63 \mathrm{~b}$ & 88.05 & -7.455 & 29.27 \\
S-21-3-6 & $1.97 \pm 0.10 \mathrm{c}$ & 78.69 & -5.830 & 31.52 \\
Ilpum & $2.97 \pm 0.46 \mathrm{a}$ & 89.10 & -8.290 & 27.57 \\
Baekjinju & 83.78 & -7.690 & 26.31
\end{tabular}

${ }^{1)}$ The data are presented as the Mean $\pm \mathrm{SD},{ }^{*}$ In a column, means followed by a common letter are not significantly different at the $1 \%$ level by DMRT.

However, application of the same force within a short period of time during milling can greatly improve the efficiency of the operation. Process using rice flour processing products through a variety of changes take place. For example, browning of rice powder occurs due changes in the primary pigment in addition to the rice flour, glucose, fat, and amino group-containing water, and these changes can have positive or negative effects. Flour processing products and chromaticity values are closely related. The $\mathrm{L}$ and a values of the donor plant indicated bright colors, while a low $\mathrm{b}$ value was measnured for "Baekjinju". The milling process can lead to a reduction in the starch density of the fine pore structure of rice flour. Are known to affect the processing characteristics of starch damage increases rapidly hydrated by amylose enzymes and moisture, is damaged starch, rice floury [28]. "S-21-3-8" showed the lowest starch damage in response to milling and was found to be suitable for the processing of brown rice flour (Table 4).

\subsection{Starch Structure of Opaque Endosperm Mutants in Brown Rice}

Round and loose aggregation of starch granules were observed upon SEM analysis of "opaque endosperm" mutants. As shown in Figure 2, opaque mutants have floury-white endosperms and exhibit a lack of light transmittance due to the aberration of starch accumulation during ripening stages. Furthermore, the shape of the

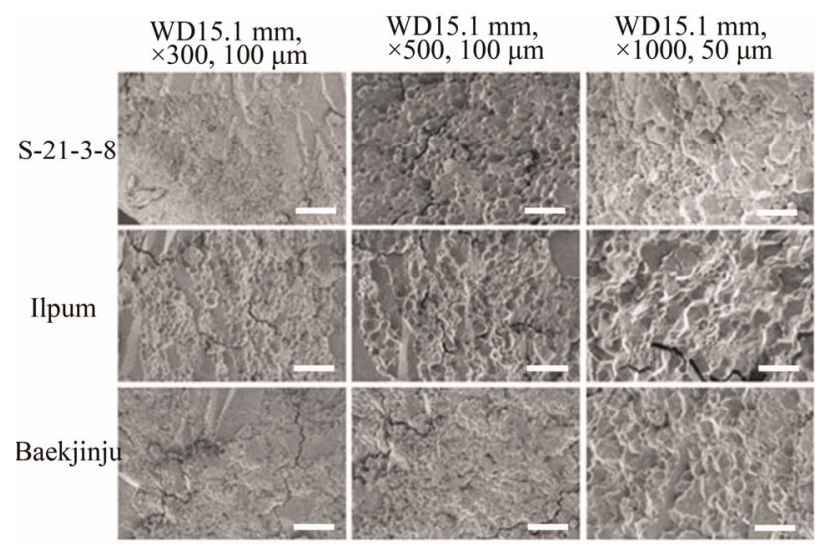

Figure 2. Comparison of starch structures on cross-sectioned grains of brown rice.

starch granules indicates that opaque endosperms were capable of degrading starch through the cleavage of large molecules of starch into smaller fragments. Conversely, endosperms of the donor plant were angulated and dense. Analysis of the chemical composition of opaque endosperms suggests that opaque mutants can be distinguished based on their arrangement on the starch granule, as well as their amylose contents. This property is related to its synthesis of amylose because it changed to a chalky endosperm [29]. Rice starch in starch grains was mostly small and of relatively uniform particle size $(2-10 \mu \mathrm{m})$, the spherical within cells but when the separation is a complex starch. 


\section{Conclusion}

A total of 14 opaque endosperm lines derived from seedderived callus culture of the rice cultivars "Ilpum" and "Baekjinju", which show low amylase and are suitable for consumption, were applied for the present study. Starch content in agricultural traits and grain quality characteristics were genetically fixed by successive selection. To select processing properties, the agricultural characteristics, grain traits, chemical and physicochemical analysis and the endosperms of the starch structure were analyzed. "S-21-3-8" was found to be similar to agricultural cultivars and have good quality comparable to that of the donor plant "Ilpum" was selected for palatability performance of low-amylose, floury rice in a suitable processability.

\section{Acknowledgements}

This work was supported by a grant from the Next-Generation BioGreen 21 Program (No. PJ0095052013), Rural Development Administration, Republic of Korea. Following are some results of a study on the "Leades IndustryUniversity Cooperation" Project, 2012-D-0033-010116, supported by the Ministry of Education, Science \& Technology (MEST).

\section{REFERENCES}

[1] L. J. Unnevehr, B. Duff and B. O. Juliano, "Consumer Demand for Rice Grain Quality," International Rice Research Institute, Manila, and International Development Research Center, Ottawa, 1992.

[2] Y. H. Choi, K. H. Kim, H. C. Chio, H. G. Hwang, Y. G. Kim, K. J. Kim and Y. T. Lee, "Analysis of Grain Quality Properties in Korea-Bred Japonica Rice Cultivars," Korean Journal of Crop Science, Vol. 51, No. 7, 2006, pp. 624-631.

[3] H. D. Mo, "Quality Improvement of Rice Grain in China," Scientia Agri Sinica, Vol. 26, No. 4, 1993, pp. 8-14.

[4] P. J. Larkin and W. R. Scowcroft, "Somaclonal Variation-A Novel Source of Variability from Cell Cultures for Plant Improvement," Theoretical and Applied Genetics, Vol. 60, No. 4, 1981, pp. 197-214. doi:10.1007/BF02342540

[5] Q. J. Xie, C. Ruch and J. H. Oard, "Homozygous Variation in Rice Somaclones: Non Random Variation Instead of Mitotic Recombination," Crop Science, Vol. 35, No. 4, 1995, pp. 954-957. doi:10.2135/cropsci1995.0011183X003500040002x

[6] K. Oono, "Putative Homozygous Mutations in Regenerated Plants of Rice," Molecular and General Genetics MGG, Vol. 198, No. 3, 1985, pp. 377-384. doi:10.1007/BF00332926

[7] J. Cao, M. C. Rush, M. W. Nabors, Q. J. Xie, T. P. Croughan and E. Nowick, "Development and Inheritance of Somaclonal Variation in Rice," In: S. K. Dutta and C.
Sloger, Eds., Biological Nitrogen Fixation Associated with Rice Production, Oxford and PIBH Publishing, New Delhi, 1991, pp. 382-420.

[8] J. K. Sohn, G. H. Yi, B. G. Oh and S. J. Lim, "Variation of Some Agronomic Traits in Anther-Derived Rice Plants," Korean Journal of Breeding, Vol. 27, No. 4, 1995, pp. 404-408.

[9] S. J. Lim, H. G. Hwang, B. G. Oh, M. H. Nam, D. Y. Kwak, G. H. Yi and N. B. Park, "Variation of Physicochemical Characteristics of Grain in Rice Plants Derived from Cell Culture," RDA Journal of Crop Science, Vol. 40, No. 2, 1998, pp. 9-13.

[10] M. Yamagishi, K. Itoh, T. Koba, Y. Sukekiyo, K. Shimamoto and T. Shimada, "Characteristics of Genetic Variation in the Progenies of Protoplast-Derived Plants of Rice Oryza sativa cv. Nipponbare," Theoretical and Applied Genetics, Vol. 94, No. 1, 1997, pp. 1-7. doi: $10.1007 / \mathrm{s} 001220050374$

[11] T. Nishi, Y. Yamada and E. Takahashi, "Organ Dedifferentiation and Plant Restoration in Rice Callus," Nature, Vol. 219, 1968, pp. 508-509. doi:10.1038/219508a0

[12] J. K. Sohn, O. H. Kwon, S. T. Cheong and I. K. Rhee, "Variation of Agronomic Characters in Regenerated Plants from Callus Culture of Rice," Korean Journal of Breeding, Vol. 23, No. 3, 1991, pp. 181-187.

[13] G. W. Schaeffer, F. T. Sharpe and J. T. Dudley, "Rice Protein Mutant Expressed in Liquid Suspension Cultures: Chitinase, B-Glucannases and Other Proteins," Theoretical and Applied Genetics, Vol. 84, No. 1-2, 1992, pp. 26 32. doi:10.1007/BF00223977

[14] P. Sathish, L. O. L. Gamborg and M. W. Nabors, "Rice Anther Culture: Callus Initiation and Androclonal Variation in Progenies of Regenerated Plants," Plant Cell Reports, Vol. 14, No. 7, 1995, pp. 432-436. doi:10.1007/BF00234049

[15] W. S. Gideon, F. T. Sharpe, H. I. Carnahan and C. W. Johnson, "Anther and Tissue Culture-Induced Grain Chalkiness and Associated Variants in Rice," Plant Cell, Tissue and Organ Culture, Vol. 6, No. 2, 1986, pp. 149-157.

[16] A. B. Mandal, M. M. Ansari. T. V. R. S. Sharma and A. K. Bandyopadhyay, "Somaclonal Variation for Disease Resistance in Indica Rice," Rice Biotechnology Quarterly, Vol. 23, No. 1, 1995, pp. 8-9.

[17] Q. J. Xie and M. C. Rush, "Somaclonal Variation for Disease Resistance in Rice (Oryza. sativa. L.)," In: B. T. Grayson, et al., Eds., Pest Management in Rice, Elsever Applied Science, New York, 1990, pp. 491-519. doi:10.1007/978-94-009-0775-1 41

[18] M. Kawata, S. Harada, B. Antonio and K. Oono, "Protoclonal Variation of Plant Regeneration in Rice," Plant Cell Tissue and Organ Culture, Vol. 28, No. 1, 1992, pp. 1-10. doi:10.1007/BF00039909

[19] G. Gavazzi, C. Tonelli, G. Todesco, E. Arreghini, F. Raffaldi, F. Vecchio, G. Barbuzzi, M. Biasini and F. Sala, "Somaclonal Variation versus Chemically Induced Mutagenesis in Tomato (Lycopersicon esculentum L.)," Theoretical and Applied Genetics, Vol. 74, No. 6, 1987, pp. 733-738. doi:10.1007/BF00247550

[20] P. J. Larkin, P. M. Bank, R. Bhati, R. I. S. Brettelli, P. A. 
Davies, S. A. Ryan, W. R. Scowcroft, L. H. Spindle and G. T. Tanner, "From Somatic Variant to Variant Plants: Mechanisms and Applications," Genomes, Vol. 31, No. 2, 1989, pp. 705-711. doi:10.1139/g89-128

[21] O. E. Nelson and D. Pan, "Starch Synthesis in Maize Endosperms," Annual Review of Plant Physiology and Plant Molecular Biology, Vol. 46, 1995, pp. 475-496. doi:10.1146/annurev.pp.46.060195.002355

[22] B. G. Hunter, M. K. Beatty, G. W. Singletary, B. R. Hamaker, B. P. Dilkes, B. A. Larkins and R. Jung, "Maize Opaque Endosperm Mutations Create Extensive Changes in Patterns of Gene Expression," Plant Cell, Vol. 14, No. 10, 2002, pp. 2591-2612. doi:10.1105/tpc.003905

[23] K. Y. Ha, J. K. Lee, Y. D. Kim and S. Y. Lee, "Grain and Brewing Characteristics in Some Rice Varieties," Korean Journal of Breeding, Vol. 28, No. 3, 1996, pp. 283-288.

[24] B. O. Juliano, "Rice: Chmistry and Technology," 2nd Edition, American Association of Cereal Chemists, St. Paul, 1985, p. 774.

[25] K. H. Kim, J. H. Lee and Y. H. Cho, "Development and Genetic Analysis of Near Isogenic Lines for Opaqueness of Endosperm in Rice," Korean Journal of Breeding, Vol. 34, No. 2, 2002, pp. 95-99.

[26] H. J. Koh, K. W. Cha and M. H. Heu, "Inheritance and Some Physicochemical Properties of Newly Induced "LowAmylose Endosperm Mutants in Rice," Korean Journal of Breeding, Vol. 29, No. 3, 1997, pp. 368-375.

[27] J. R. Son, J. H. Kim, J. I. Lee, Y. H. Youn, J. K. Kim, H. G. Hwang and H. P. Moon, "Trend and Further Research of Rice Quality Evaluation," Korean Journal of Crop Science, Vol. 47(S), 2002, pp. 33-54.

[28] F. Meuser, R. W. Klingler and E. K. Niediek, "Characterization of Mechanically Modified Starch," Starch, Vol. 30, No. 11, 1978, pp. 376-384. doi:10.1002/star.19780301105

[29] H. G. Kang, S. H. Park, M. Matsuoka and G. H. An, "White-Core Endosperm Floury Endosperm-4 in Rice Is Generated by Knockout Mutations in the C4-Type Pyruvate Orthophosphate Dikinase Gene (OsPPDKB)," The Plant Journal, Vol. 42, No. 6, 2005, pp. 901-911. doi:10.1111/j.1365-313X.2005.02423.X 